\title{
UMA PERSPECTIVA SOBRE A POLÍTICA DE PROMOÇÃO DA LEITURA NO MUNICÍPIO DO RIO DE JANEIRO
}

\author{
AXER, Bonnie ${ }^{1}$
}

\begin{abstract}
RESUMO
Atualmente, as salas de leitura das escolas regulares do município do Rio de Janeiro são espaços que envolvem leitura, meios de informação e múltiplas linguagens. É este o ponto que me interessa na configuração das Salas, ressaltando que mudanças políticas mais amplas na Prefeitura e da Secretaria Municipal de Educação do Rio de Janeiro (SME/RJ) (re)configuram esses espaços e as concepções que norteiam o trabalho. Para entender algumas das mudanças ocorridas, analisei os três últimos documentos oficiais desses espaços: a Resolução n0560 de 1996, o fascículo de atualização do Núcleo Curricular Básico Multieducação - Multieducação Temas em Debate: Sala de Leitura - de 2006, e a Resolução n⿳01072 de 2010, que traz, a partir do projeto "Rio uma cidade de leitores", uma nova proposta de funcionamento para esses espaços. Analiso tais movimentos a partir da concepção de currículo enquanto enunciação cultural (MACEDO, 2007), na perspectiva de que, embora se busque algo novo, o currículo traz rastros e os partilha no momento da criação de sentidos outros.
\end{abstract}

PaLAVRas-Chave: Currículo - Política - Leitura.

\begin{abstract}
Currently, the reading rooms in regular public schools in the city of Rio de Janeiro are spaces that involve reading, media and multiple languages. This is the point that interests me in the configuration of the rooms, noting that broader policy changes at the City Hall and the Municipal Office of Education of Rio de Janeiro (re)configure these spaces and concepts that guide the work. To understand some of the changes, I analyzed the last three official documents of these spaces: Resolution No. 560 of 1996, which updates the Basic Curriculum Multieducation - Multieducation Issues in Debate: Reading Room - 2006, and Resolution No. 1072 of 2010, which brings, from the project "Rio a city of readers," a new working proposal for these spaces. I analyze such movements from the curriculum design as cultural enunciation (Macedo, 2007), on the view that, although the curriculum seeks for something new, it brings traces and share them at the time of creation of other senses.
\end{abstract}

KEYWORDS: Curriculum - Policy - Reading.

\footnotetext{
${ }^{1}$ Professora substituta na Faculdade de Educação da Universidade do Estado do Rio de Janeiro e no Instituto de Aplicação Fernando Rodrigues da Silveira - CAp-UERJ. E-mail: bonnieaxer@yahoo.com.br
} 


\section{INTRODUÇÃO}

"As escolas da Rede Pública Municipal de Ensino da Cidade do Rio de Janeiro contam com um espaço especial, voltado para a promoção da leitura e a formação de leitores: A Sala de Leitura" (Rio de Janeiro. SME, 2006, p.6).

Trago neste artigo uma perspectiva a respeito das Salas de Leitura, espaços que, desde 1985, possuem na Rede Municipal do Rio de Janeiro um trabalho destinado à leitura e que envolve os temas de leitura, tecnologias e múltiplas linguagens. São essas diferentes configurações que me interessam ao atentar para as Salas de Leitura das escolas regulares do município do Rio de Janeiro, ressaltando que mudanças políticas mais amplas na Prefeitura e na Secretaria Municipal de Educação do Rio de Janeiro (SME/RJ) (re) configuram estes espaços e as concepções que norteiam os mesmos.

As salas de leitura foram criadas em 1985. A partir de então, há uma série de resoluções que organizam o trabalho desse espaço. Neste trabalho me deterei nos três últimos, como já explicitado.

Para entender algumas das mudanças ocorridas nesses espaços, considerando os temas mencionados acima, utilizo como metodologia a análise dos três últimos documentos oficiais que norteiam o trabalho desenvolvido nesses espaços: a Resolução n0560/1996, que definiu o funcionamento das Salas de Leitura dentro da Rede Municipal de Ensino do Rio; o fascículo de atualização do Núcleo Curricular Básico Multieducação - Multieducação Temas em Debate: Sala de Leitura - de 2006, que (re)significou e aprofundou os sentidos da resolução de 1996 e, por fim, a Resolução n01072/2010, que traz, a partir do projeto "Rio, uma cidade de leitores", novas propostas de funcio- namento para esses espaços. Vale ressaltar ainda que os três documentos supracitados apresentam sentidos e concepções que caracterizam as diferentes gestões que se encontram (ou encontravam) no poder no momento de cada uma das produções.

Para tanto, estruturo este trabalho da seguinte forma: primeiramente farei uma apresentação dos aportes teóricos que me fundamentam para pensar tais discussões. Em sequência, busco maior entendimento em torno do processo social de construção de formações discursivas provisórias dos documentos que norteiam o trabalho das Salas de Leitura, buscando perceber as relações contingenciais entre os diferentes discursos e demandas. $E$, por fim, analiso os documentos selecionados para este trabalho e alguns depoimentos cedidos em entrevista devidamente gravada e transcrita com a atual coordenadora da Gerência de Mídia e Educação da Secretaria Municipal do Rio de Janeiro (SME/RJ) - Departamento responsável pelas Salas de Leitura, para melhor compreender o processo de produção dessas políticas.

\section{Falando Um pouco de currículo e POLÍTICA}

Analiso os movimentos que envolvem as resoluções e documentos da Sala de Leitura a partir da concepção de currículo, enquanto enunciação cultural (MACEDO, 2007), na perspectiva de um currículo que, embora busque algo novo, traz também rastros que foram construídos historicamente e que são partilhados no momento da criação de novos sentidos. Opero com a concepção de currículo enquanto espaçotempo de fronteira onde é possível a existência de relações interculturais e um poder oblíquo e contingente. Ou seja, onde discur- 
sos globais e locais negociam a sua existência no momento de (re) criação de sentidos.

Trabalho com o currículo como espaço-tempo de fronteira. Mas que fronteira é essa? Trata-se de uma fronteira onde os sujeitos, que são híbridos ${ }^{2}$ por si só, a partir de seus pertencimentos culturais, interagem com outros híbridos produzindo híbridos outros. Esta noção de hibridismo me auxilia, portanto, no entendimento de que nenhum sistema cultural se constitui sem a presença da diferença (HALL, 2003), pois a mesma existirá sempre. No entanto, é preciso ressaltar que essa relação não é realizada com base na tolerância, mas sim da negociação, que possibilita a aceitação de diferentes culturas. É assim que defendo a prática híbrida do currículo, concebendo o mesmo enquanto espaço de fronteira.

Opero ainda com a perspectiva de um currículo cultural, um currículo como produção cultural, que vai além das inúmeras dicotomias que existem no campo (currículo vivido/currículo oficial, currículo praticado/currículo escrito). Penso o currículo enquanto uma produção cultural marcada pela negociação entre discursos culturais que estão constantemente em disputa para significar o mundo. Ao descrever e pensar o currículo como uma produção cultural, não trago aqui a visão de uma cultura universal, ou de uma cultura que seja superior e por isso desejada. Penso na cultura para além de repertórios de saberes e significados que são partilhados historicamente e são passados de geração para geração, mas também como um lugar de enunciação (BHABHA,

\footnotetext{
2 Embasada em Canclini (2006) entendo, a partir do hibridismo, que numa relação entre diferentes culturas não há mais uma "Cultura que supere a Outra", mas sim um espaço onde é possível a convivência, a negociação e a articulação entre esses diferentes discursos culturais, permitindo consequentemente a formação de outros discursos culturais a partir de tal interação.
}

2003), um espaço de criação.

A partir dessa perspectiva interativa da cultura, percebo-a como algo composto e recomposto constantemente. Trata-se de uma construção contínua de sentidos, a partir da relação entre uma ampla variedade de fontes resultantes de um processo híbrido e fluido. Vivemos hoje o que interpreto como fluxo cultural, fruto da globalização e da ampliação do contato intercultural resultante dos avanços tecnológicos (MACEDO, 2010). Ao pensar a partir de um fluxo de culturas, me apoio novamente na autora ao dizer que:

O momento atual poderia ser resumido por uma palavra: fluxo. Fluxo de capital, de informação e idéias, de pessoas. Em conjunto, tais fluxos dificultam a sobrevivência de totalizações e explicitam as diferenças. Fica mais difícil referir-se à cultura da humanidade ou a culturas nacionais quando as nações estão em risco e as culturas locais ganham visibilidade (MACEDO, 2010, p.9).

É com esta mesma percepção a cerca da cultura que concebo o currículo. A partir dessa perspectiva de fluxo, penso o currículo enquanto uma construção de sentidos que não se completa, sendo contingente provisória e inacabada. Desse modo, acredito que no momento de construção do currículo exista uma fixação de sentidos que, embora fixe momentaneamente discursos e práticas, os mesmos se modificam a cada contexto cultural, histórico, social e político. Trabalho a partir de um fluxo constante onde se produzem sentidos inúmeros que validam posturas e discursos que são postos e negociados na produção curricular. Interpreto ainda tais sentidos, sendo politicamente construídos e desconstruídos a todo o momento. Assim, falo de um currículo ambivalente e contingente cuja sua políti- 
ca se fecha provisoriamente e se atualiza a cada novo contexto e a cada nova demanda.

Trabalhar então com o currículo, enquanto espaço-tempo de fronteira e a cultura enquanto enunciação, traz implicações diretas de como compreender o poder. Penso então um poder híbrido (CANCLIN, 2006), que exige outra concepção de política e de hegemonia. Sendo assim, acredito que os textos curriculares são textos coletivos e contingenciais, e na Sala de Leitura não acontece diferente. Acredito que tais textos são produzidos e contextualizados, visto que parto da ideia de Mainardes (2006) de que a política curricular não é finalizada e fixada no momento de sua criação, mas penso que estes textos políticos podem e precisam ser (re)lidos, (re)contextualizados e (re)significados em relação ao tempo e ao local específico de sua produção.

Para pensar então numa política curricular pautada na contingência, uma política curricular que não traz, a meu ver, uma verdade única, mas sim diversas interpretações, formas de significar e conceber um futuro é que compartilho com as ideias de Lopes (2005, 2008 e 2010), Ball (1992 e 2001) e Laclau (2004, 2005), quando me auxiliam a pensar a política como algo inacabado e recontextualizado a todo o momento num ciclo contínuo de produção cultural.

Embasada em Lopes (2010), venho desenvolver outra forma de pensar e olhar para as políticas de currículo, defendendo

(...) ser possível, teórica e politicamente, admitir o descentramento, a fluidez, a ausência de estruturas auto-explicativas e os projetos com uma dada direção a priori, bem como admitir, simultaneamente, nossa necessidade provisória e contingencial de estabelecer centros e projetos. (LOPES, 2010, p.30).

Assim como a autora, acredito que, embora pensemos, levando em consideração a fluidez das decisões, demandas e discursos que perpassam a construção curricular, para nos comunicarmos, para fazermos política -as políticas curriculares -, reconheço que em grande parte das vezes é preciso fixar, ainda que provisoriamente, identidades, significações, decisões e discursos numa determinada política curricular. Mas, da mesma forma, reconheço que tais fixações são momentâneas e podem ser reconfiguradas durante todo o processo de produção. É assim que interpreto os documentos que embasam o trabalho das Salas de Leitura.

Para tanto, concebo a política, também embasada em Lopes (2008), como texto e discurso. Nesse sentido, a política enquanto texto possibilita uma multiplicidade de leituras que permite a criação de algo novo. Já a política, enquanto discurso, é a dimensão do próprio político, ou seja, práticas institucionais que criam uma ordem com um caráter mais normativo e sem uma totalidade. $\mathrm{E}$ é dentro dessa perspectiva, atuando com a política com discurso e texto, que me contraponho ao fechamento engessado das políticas curriculares, pois acredito que quanto mais fechada e controladora é a política curricular, menor é o espaço de criação e adesão dos docentes à mesma.

Assim, a política curricular encarada como texto e discurso permite inúmeras leituras que possibilitam a compreensão de um currículo elaborado num movimento e numa produção inacabada que envolve múltiplos contextos. Tal percepção nos auxilia no entendimento do Estado articulado com as micropolíticas. Coloco-me, assim, contrária a uma visão Estadocêntrica de política, 
pois acredito que tal abordagem não nos permite perceber a complexidade que está por trás de uma produção curricular.

Segundo Laclau (2005), a partir da dimensão do político, onde existem consensos conflituosos, relação entre adversários e decisões contingentes tomadas num terreno indecidível, é necessário um fechamento momentâneo e provisório de algumas particularidades - é o que o autor chama de cadeia de equivalentes - para que haja diálogo e negociação entre diferentes demandas. Por isso o autor defende um fechamento contingente onde tal grupo, nesse caso penso os grupos envolvidos na construção curricular, se estrutura em torno de uma semelhança que os equivale. Cria-se então uma totalidade que é assumida como universalidade dentro de uma cadeia equivalencial não fixa. Tal totalidade particular, assumida como universal, é a interpretação que 0 autor possui de hegemonia, interpretação com a qual também opero.

Esta estrutura não fixada se constrói a todo o momento, pela própria ação e posição do sujeito e de suas demandas. Tal perspectiva me faz encarar toda política curricular sem um fechamento engessado, mas fixado provisoriamente, com fixações e aberturas atualizadas a cada novo contexto e a cada nova demanda. Acredito que no momento de construção do currículo, a construção constante de sentidos que ali ocorre sofre uma fixação momentânea, mas pode se modificar a cada nova identificação. Diante do acima exposto, identifico que um exemplo interessante a ser analisado no presente trabalho é do fascículo de atualização da Multieducação "Salas de Leitura temas em debate", que será apresentado mais a frente.

Considero e defino, ainda, o currículo como uma produção cultural, onde todos os atores sociais precisam estar e estão envol- vidos em sua elaboração. Nesse sentido, trago a compreensão de Ball e colaboradores (1992), quando nos dizem que os profissionais que atuam nas escolas não estão excluídos do processo de formulação e implementação das políticas, mas também as produzem e (re)significam nos diferentes contextos onde passam. Os sujeitos curriculares também são formuladores de política, pois os textos curriculares são produzidos num processo político, onde diversas representações são hibridizadas.

Esta perspectiva de Ball e colaboradores (1992), revisitada por Lopes (2008, 2010), me ajuda entender os processos de continuidade da construção curricular através de uma abordagem da política que considera a existência de três diferentes contextos: influência, produção e prática, que compõem o ciclo contínuo de políticas de Ball. Cabe ressaltar que, na perspectiva deste ciclo contínuo, essas três esferas encontram-se profundamente interligadas e a relação entre elas não é hierárquica e nem linear, mas de fato contínua, a partir de um ciclo. O contexto de influências está associado ao momento em que as decisões políticas são tomadas e os discursos são construídos (organismos internacionais, partidos políticos, governo e redes sociais do poder legislativo). Os jogos de poder que se dão nessa arena são profundos e mobilizam acordos entre grupos com interesses diversos. Atrelado a estes está o contexto de produção do texto político, que se refere ao momento em que aquilo que se encontrava no plano das ideias é sintetizado para o acesso de um público com interesses mais gerais. Por fim, temos o contexto da prática, que mostra que o texto não se finaliza no momento de sua elaboração, podendo ser contextualizado de acordo com os diferentes locais onde serão apropriados.

A principal contribuição que trago 
do ciclo contínuo de políticas é a não implementação das políticas curriculares de forma mecânica. Acredito que a aceitação da proposta vai além da implementação e o autor me ajuda a pensar que as políticas curriculares podem ser e são (re)criadas e (re) significadas continuamente. Ou seja, me permite perceber os tantos efeitos que as ações centralizadas, os marcos políticos e econômicos são gerados também das ações cotidianas e locais e as mesmas interferem nas agências políticas. $O$ não fechamento da estrutura trazido por Laclau (2004, 2005) muito contribui para essa lógica da continuidade do ciclo de políticas e consequentemente para meu entendimento a respeito das mudanças e movimentos que existem na organização, nos discursos e nos documentos das Salas de Leitura.

Sendo assim, penso ser o currículo uma produção cultural que não desconsidera as especificidades existentes em cada política e que reconhece a produção do conhecimento presente em cada instância do processo de sua produção. Com base nas concepções trazidas aqui, construo e compartilho com os autores aqui já apresentados uma visão outra do currículo, que está além da seleção de saberes da cultura dominante - discursos homogêneos - mas sim um espaço-tempo onde podem ser negociadas diferentes culturas e perspectivas.

\section{OlHando para algumas políticas}

Com o embasamento teórico apresentando anteriormente, trago os últimos três documentos que organizam o funcionamento das Salas de Leitura, onde busco perceber as movimentações e os discursos que perpassam os diferentes momentos políticos que a Rede Municipal do Rio de Janeiro passa e que acaba tendo tais momentos marcados em seus documentos.
Para me auxiliar em tal análise, trago ainda trechos da entrevista que realizei no dia 11 de maio de 2013 com coordenadora da Gerência de Mídia e Educação da SME/RJ, que é também a redatora final do único documento curricular que a Sala de Leitura possui e que mais a frente apresentarei. A mesma me recebeu SME/RJ para me fornecer seu depoimento, gravado com seu consentimento.

O primeiro documento que trago é a resolução no 560, de 11 de janeiro de 1996. Esta resolução define a atual apresentação das salas de leitura, 30 salas de leitura chamadas de Pólo e o restante, salas de leitura Satélite. Essa configuração foi anunciada em $1992^{3}$, quando as Salas de Leitura Pólo foram criadas (Portaria no 36/92/E-DGE -22/09/92), salas estas que passam a dispor de acervo ampliado de equipamentos eletrônicos, servindo de suporte e apoio para as demais salas de leitura, as chamadas Salas de Leitura Satélites.

A resolução de 1996 então confere, pela primeira vez em documento oficial, a responsabilidade de colocar em prática a proposta dos Núcleos de Mídia Educação nas 30 Salas de Leitura Pólo ${ }^{4}$ aos professores das mesmas. Para isso, esses profissionais passam a ter a necessidade de possuírem conhecimentos especializados em Gerência de Projetos Mídia Educativos, além das atribuições apontadas em resoluções antecedentes. Nesse sentido, estes professores passam a participar de oficinas e cursos destinados somente aos professores de sala de leitura. O professor da Sala de Leitura passa agora a gerenciar os recursos de

\footnotetext{
${ }^{3}$ Ver esta discussão também em AXER (2009).

${ }^{4} \mathrm{Em}$ resoluções anteriores, as salas de leitura foram divididas em satélites e pólo. As salas pólo trabalham, então, em prol do funcionamento das satélites. É nas salas pólos que ficam ainda os maiores acervos de materiais audiovisuais
} 
mídia educacional, devendo propiciar a participação de professores e alunos em um processo de produção coletiva e orientar a discussão, com os demais professores, sobre as práticas a serem desenvolvidas em relação aos programas veiculados pela MULTIRIO $^{5}$, que passa agora e ter um dinamizador de seus produtos nas escolas.

Dentro dessa nova configuração, passam a ser algumas das atribuições das salas: promover atividades que compreendam empréstimos do acervo, orientação à pesquisa, oficinas, exposições, feiras, concursos, sessões de vídeo com debates, rodas de leitura, encontro com autores, produção de programas de vídeo, de rádio, jornais, sites, tendo sempre como objetivo estimular a criatividade, o senso crítico e a produção do conhecimento. Embora tenham sido pensadas, a princípio, como espaços de práticas leitoras de textos estritamente literários, nesse momento, as Salas de Leitura encontram-se também definidas como espaços multimidiáticos. Assim, a concepção de leitura se alarga de tal forma, que as Salas, a meu ver, passam a ser espaços de multimeios, espaços onde as diversas tecnologias e mídias existentes na escolas ganham visibilidade. As Salas agora precisam, além de promover a leitura, dinamizar os meios tecnológicos na escola.

É interessante mencionar que 1996, além de ser ano da grande resolução que regulamentará o funcionamento das salas de leitura por mais de dez anos, é também o ano da distribuição do Núcleo Curricular Básico Multieducação a toda a Rede Municipal do Rio. Embora a rede do Rio de Janeiro esteja apresentando desde o ano de 2009

\footnotetext{
${ }^{5}$ A MULTIRIO é a Empresa de Multimeios da Prefeitura do Rio de Janeiro, responsável pela produção de programas de TV, vídeos, sites, CD-ROM e publicações voltadas prioritariamente para a Rede Municipal de Ensino do Rio de Janeiro.
}

novos documentos curriculares, consequências da nova gestão que se iniciou em 2009, a Multieducação é, ainda hoje, o currículo oficial que rege as escolas do Município do Rio de Janeiro. A mesma foi criada e distribuída a toda a rede, fundamentalmente com a intenção de "lidar com os múltiplos universos que se encontram na escola" (NCBM, p.108), buscando uma unidade na diversidade. Buscava-se com a sua criação uma unidade na própria rede, visto que estamos falando de uma rede grandiosa, que hoje abarca cerca de 1.062 escolas.

Procurava-se, então, um documento curricular que falasse a todas as escolas. Embora as salas de leitura não sejam mencionadas nesse documento, as mesmas sofrem uma ampliação em seu trabalho, que a partir de então passa a ser afinado com a perspectiva de outras linguagens. Em entrevista com a atual coordenadora ${ }^{6}$ da Gerência de Mídia e Educação da SME/RJ, ela nos explica o motivo da não entrada das Salas na Multieducação:

\begin{abstract}
"Ela não entra no documento curricular por quê? Porque não era entendido naquele momento que, a perspectiva que se tinha naquele momento era que se a sala de leitura entrasse como ingrediente fixo no currículo, ela poderia ser engessada como uma disciplina: hora da sala de leitura, com tempos de aula, grade (...). Então a idéia era que ela fosse entendida como um projeto especial (...)".
\end{abstract}

Esse é um fato que muito me chama a atenção nesse documento curricular, visto que é distribuído a todas as escolas em

\footnotetext{
6 Tendo a mesma ocupado o mesmo cargo nas gestões anteriores, a entrevistada é ainda redatora final do fascículo de atualização da Multieducação, que será apresentado mais a frente. Vale destacar ainda que a mesma é uma pessoa extremamente importante para a história das Salas de Leitura.
} 
1996, mas somente em 2006, após 10 anos da sua implantação e após 21 anos do surgimento das salas de leitura nas escolas regulares da rede, é que a Multieducação fala diretamente das intenções e do trabalho das salas de leitura, em um de seus fascículos de atualização. Até então, a as salas de leitura funcionavam com diretrizes e documentos próprios internos.

Algumas orientações da Resolução de 1996 mencionadas anteriormente foram ressignificadas pelo fascículo de atualização, já minimamente anunciado. Tal fascículo se intitula "Sala de leitura" - Temas em debate, que foi produzido pela anteriormente denominada Divisão de Mídia e Educação ${ }^{7}$, em 2006. É esse o segundo documento que trago para tecer meu olhar sobre as salas de leitura. O mesmo redirecionou alguns aspectos do trabalho, assinalando a necessidade de se rever as funções destinadas ao professor da Sala de Leitura descritas na resolução já mencionada.

Vale destacar que a criação desse e de outros fascículos de atualização se deu a partir de 2003, num contexto onde o Departamento Geral de Educação realizou consultas sistemáticas aos diferentes níveis de atuação da Secretaria Municipal de Educação, objetivando a Atualização da Multieducação. Nortearam a discussão alguns questionamentos, como: O que falta? ; O que deveria ser aprofundado? ; Sugestões para

\footnotetext{
7 Tal divisão mudou de nome na atual gestão, mas vale lembrar que eram algumas das atribuições nessa época: Planejar e coordenar o processo de acesso de professores e alunos aos meios de comunicação e suas linguagens; Propor políticas de capacitação para professores regentes dos Núcleos de Mídia Educação e Salas de leitura; Ampliar a acervo de material especializado nos Núcleos de Mídia Educação e nas Salas de leitura, entre outras.
}

a atualização da proposta. Dentro de tantos, as Salas de Leitura foram uma das demandas para se ter uma publicação. Assim, as Salas ganham um documento que pela primeira vez traz muito claramente a proposta de trabalho das mesmas dentro das escolas da Rede Municipal do Rio de Janeiro. A este respeito, a coordenadora da Gerência de Mídia da SME/RJ indica que:

\begin{abstract}
"Anos mais tarde, quando a Multieducação fez dez anos, a avaliação que se tinha naquele contexto era outra. Não! Agora a gente precisa justamente dar um status de atividade integrada ao currículo da escola. Que tem uma identidade própria, mas que precisa dialogar! E aí, politicamente também se avaliava que era uma iniciativa importante reconhecer esse trabalho e a identidade dele dentro da rede".
\end{abstract}

É assim que as Salas de Leitura ganham maior visibilidade. Esse fascículo, que agora é foco de meu olhar é o único documento curricular que existe a respeito das Salas de Leitura. Mas por que digo isso? Porque todos os documentos curriculares até então existentes não eram oficiais, ou melhor, não faziam reconhecer na própria Rede a seriedade do trabalho que ali estava acontecendo. As resoluções, documentos até então existentes, eram destinados somente aos professores da Sala de Leitura, direção e coordenação. Já esse fascículo da Multieducação, assim como a própria, foi distribuído a toda a Rede, o que fez com que a Sala de Leitura ganhasse visibilidade na própria Rede Municipal. Vale ressaltar ainda que, com esse fascículo, é reconhecido também o trabalho dos professores, que agora se sentem representados na Rede ao serem incorporados no documento curricular vigente.

O fascículo em questão é um documento bem estruturado e embasado teori- 
camente, com autores contemporâneos e relevantes na área da leitura. Esse currículo tem o objetivo de apresentar os principais aspectos que constituem tal trabalho, buscando situá-lo no contexto da escola e ampliando o diálogo estabelecido com a Rede Pública Municipal de Ensino para além dos limites de cada Sala de Leitura. Embora seja um documento com um cunho basicamente teórico, o mesmo nos dá ideia do funcionamento das salas. Nesse sentido, representa um marco importante na trajetória do trabaIho que vinha sendo construído nas Salas, visto que propõe e coloca em discussão a necessidade do desenvolvimento de ações que relacionem leitores, textos e diferentes leituras, considerando a leitura como uma atividade que pode ser dar tanto dentro como fora da escola.

A proposta se constitui, portanto, num poderoso instrumento de aproximação entre leitores e leituras, traduzindo-se num convite a toda a comunidade escolar para o encontro com diversos textos e diferentes suportes textuais. (Rio de Janeiro. SME, 2006, p.19).

Esse fascículo traz ainda outras questões que considero cruciais para a organização do documento, como das próprias salas. Primeiramente, o documento defende uma sala que valoriza a leitura em si, o próprio ato de leitura e a não didatização da mesma:

A fim de evitar a didatização do texto, as práticas de leitura literária na escola devem favorecer o exercício da criatividade, da alegria, da fantasia e da imaginação, uma vez que o compromisso do texto literário é com o simbólico, e sua função é, sobretudo, emancipatória. (idem: p.14).

Nesse sentido, a leitura, antes cumprida de forma não-espontânea e nãodesejada, deve dar lugar às práticas inter- textuais (ibidem: p.13), onde os alunos podem e devem interagir com diferentes textos, assim como com diferentes gêneros discursivos. O documento traz uma posição antagônica em relação à imposição de um único modelo de leitura, de interpretação dos textos lidos, pois cada leitor é co-autor. Porque compreende e interpreta a partir do mundo que habita. (ibidem: p.14). As Salas de Leitura passam a ser vistas por toda a escola como espaço essencial para o exercício de práticas leitoras, em especial de uma leitura que possa ser vivida de diferentes maneiras. O trabalho nas Salas então começa a apontar para a formação de leitores capazes de dialogar com diferentes textos e suportes textuais. É a perspectiva de múltiplas linguagens que agora aparece.

A partir de tais perspectivas, o fascículo defende um espaço dedicado à leitura, de forma que esta seja vivida intensamente, mas também a promoção de leituras diversas, a partir de uma visão ampla de leitura. Assim, as diferentes mídias passam a ter espaço nas Salas de Leitura, como a TV, o rádio, o jornal, a internet, pois estes também trazem textos que possibilitam leituras das mais diversas. Com essas dimensões mencionadas acima, que reconheço sendo as norteadoras do trabalho das salas de leitura, questiono: A necessidade de articular diferentes demandas (mídias em geral) não fez com a leitura em si se perdesse? Seria a sala de leitura um lugar de encontros, ou seriam desencontros?

Acredito que a concepção de leitura desenvolvida e ampliada pelo fascículo permite uma Sala que promova encontros dos mais diversos, com leituras das mais variadas. Trata-se de uma perspectiva de leitura a partir de múltiplas linguagens, perspectiva essa que muito dialoga com a intenção da própria gestão da Secretaria naquele momento, visto que tal visão se faz presente 
em outros fascículos de atualização e nos próprios produtos da $\mathrm{SME} / \mathrm{RJ}$ da Multirio distribuídos na época. Um exemplo é a tão conhecida série Juro que $V \beta$, uma série de desenhos animados, produzido pela Multirio em parceria com uma Sala de Leitura da Rede, onde alunos da escola tinham contato com diferentes linguagens que auxiliavam na construção de um desenho animado final.

Ao trazer estas breves apresentações de movimentos significativos no funcionamento e na representação curricular deste espaço, julgo ser extremamente relevante destacar que atualmente a SME/RJ, juntamente com a prefeitura do Estado, possui uma nova gestão, iniciada no ano de 2009. Mas essa mudança de gestão, apesar do pouco, tempo já trouxe modificações e posições significativas para o funcionamento das atuais Salas de Leitura. Sendo assim, novos sentidos e concepções vão sendo negociados com os que até então estavam postos.

Uma das primeiras propostas da nova gestão da SME/RJ foi o projeto intitulado "Um Salto de Qualidade na Educação Cario$c a^{9}$ ", projeto este que dialoga com todas as escolas a partir de outros projetos. Diante dos baixos índices de rendimento recebidos pelos alunos na Prova Brasil, especialmente em Língua Portuguesa e Matemática, criamse projetos ligados ao Salto de Qualidade que passam a ser desenvolvidos nas escolas da Rede a fim de melhorar tal situação. São estes projetos: 1.Revisão Geral de Aprendi-

\footnotetext{
8 Trata-se de uma serie de com cinco desenhos animados que valorizam o folclore brasileiro e que foram todos realizados numa sala de leitura da $3^{a}$ CRE. Uma discussão mais detalhada de tal produção encontra-se em alguns outros trabalhos meus: AXER (2008).

${ }^{9}$ Projeto integrado de intervenção para acabar com a aprovação automática e melhorar a qualidade do ensino oferecido às crianças do Rio de Janeiro.
}

zagem de Português e Matemática, 2.Recuperação de Aprendizagem, 3.Escolas do Amanhã- uma abordagem nova para a Educação em áreas de vulnerabilidade da infância e juventude, 4. Escola de Mães, 5.Rio uma Cidade de Leitores, 6.Creches que educam e 7.Universidade Virtual do Educador Carioca. Todos os projetos visam melhorar a qualidade de Educação nas escolas Municipais do Rio.

Especifico meu interesse no projeto 5: Rio uma cidade de leitores, visto que, trata-se de um projeto que necessita inteiramente da parceria com os trabalhos desenvolvidos nas Salas de Leitura e possui como principal objetivo a promoção da leitura que envolva um conjunto de ações de incentivo para uma cultura leitora carioca. Percebo aqui outro posicionamento em relação à concepção de leitura, que, nesse momento, trata-se de uma concepção de promoção de leitura em si.

Nesse sentido, as Salas de Leitura tendem a promover a articulação das ações de promoção da leitura dentro e fora da escola, um olhar mais aprofundado, mais centrado nessa questão, que já havia sido trabalhada anteriormente, mas agora ganha uma atenção especial: atender às comunidades ao redor da escola. Agora as salas se apresentam abertas, apresenta-se como uma diretriz de trabalho estabelecer parcerias da escola com seu entorno, dialogar com as bibliotecas municipais de forma mais intensa.

Segundo a apresentação que se encontrava no site da SME/RJ, tal projeto possui como principais características:

*Instalar o Conselho Carioca de Leitura; *Formar multiplicadores de leitura com professores, voluntários e bolsistas em toda a cidade, com ênfase nas Escolas da Paz; *Abrir a sala de leitura para as famílias e implantar salas de leitura em espa- 
ços ociosos nas comunidades de alta vulnerabilidade da infância e juventude; *Círculos de Leitura - selecionar os alunos mais apreciadores de leitura nas Escolas da Paz e ler com eles os melhores livros da literatura universal para cada faixa etária (a partir de 10 anos); *Levar a sala de leitura da escola ao bairro, à praça e à praia, com empréstimo de livros, contação de histórias e escritores; *Distribuir 2 livros por trimestre aos professores(...).

A partir desse projeto, a Sala de Leitura, no ano de 2009, começa a se moldar para trabalhar com tais funcionalidades, possuindo como principais ações: planejar, coordenar, executar e avaliar ações específicas do projeto "Rio uma cidade de leitores", organizar o acervo das salas tanto para a comunidade escolar como para seu entorno; elaborar plano de ação que inclua a promoção de leitura juntamente com o PPP de cada escola; estabelecer parcerias com a comunidade local, com as bibliotecas, envolver os pais em ações de promoção da leitura, priorizar as Escolas do Amanhã, apoiar a recuperação escolar (...).

Em março de 2010, as Salas ganham uma nova resolução: SME No 1072, de 31 de Março de 2010. Nessa resolução, as Salas de Leitura são apresentadas, já em seu primeiro artigo, como espaços voltados para a promoção de leitura literária, para a formação de leitores e para a realização de pesquisas escolares, funcionando como estruturas de suporte, inclusive para o reforço escolar. No mesmo parágrafo, o documento reitera que a formação do leitor implica em considerar outros suportes textuais que contemplem a diversidade de textos e formatos existentes.

Tal resolução mantém o que já havia sido descrito na resolução anterior de 1996, mas incorpora atividades que envolvam o projeto Rio uma cidade de leitores, assim como modifica a estrutura da Sala de Leitura Pólo. Nessa resolução, assinala-se a deliberação de haver somente um professor por Sala, o que é uma mudança com relação à resolução anterior, que citava a necessidade de três a cinco professores.

Assim, com esse movimento histórico das Salas, com essas modificações e ampliação das atribuições para as salas de leitura, percebo claramente a movimentação política e a legitimação de discursos que movimentam diretamente o funcionamento desses espaços. Acredito, portanto, que as mudanças de gestão modificam diretamente as salas e concordo com a coordenadora da Gerência de Mídia quando me indicou em seu depoimento que:

"(...) cada gestão traz a sua marca, seus projetos, sua identidade, então a rede tem uma trajetória que os secretários vêm e vão, passam por ai, uns são da rede outros não são da rede enfim, mas estão naquele momento naquele período, a rede não, a rede fica. $E$ a rede é o somatório de todas essas marcas que são deixadas ao longo de cada trajetória..."

\section{CONSIDERAÇÕES INACABADAS}

Embasada em minhas leituras a respeito de currículo e de funcionamento político, interpreto as atualizações e as tantas modificações de funcionamento das Salas de Leitura, assim como a própria atualização curricular que a Multieducação sofreu com a entrada de novos temas em sua discussão, como foi o caso das Salas de Leitura, enquanto uma tentativa de manutenção do trabalho que as próprias Salas de Leitura propunham originalmente, que é a promoção da leitura. Ao rever alguns de seus conceitos, ao ampliar suas discussões, as Salas trazem novos discursos que tentam a cada novo contexto dialogar com diferentes de- 
mandas: mídias e tecnologias na escola, alunos com baixos índices, professores que precisam dar reforço, em prol de um objetivo que ao longo de sua história se mantém: $o$ incentivo pelo gosto à leitura. Assim, as Salas de Leitura passam a falar a diferentes destinatários, mas com a mesma proposta em sua base.

Nesse sentido, interpreto a política curricular, e aqui em específico as políticas que moldam o trabalho das Salas, sem um fechamento definitivo, mas provisório que se atualiza e se (re) cria a cada novo contexto, a cada escola e a cada demanda. Espero e proponho um currículo Outro, que possibilita a construção para além do que está colocado no documento, mas que permita mexer e remexer nas propostas que chegam, que nos permita negociar a fim de dialogar com os atores que estão envolvidos no processo de produção. Desse modo, concordo com Laclau (2005), quando indica que numa construção política há uma construção de sentidos contínua. Dessa mesma forma penso essa produção de sentidos contínua presente no currículo das Salas de Leitura, visto que não interpreto a mesma de forma engessada.

Acredito que as Salas de Leitura se (re) configuram constantemente, levando em consideração o que está posto em cada contexto ao qual estão inseridas e às demandas com as quais dialoga no momento de legitimação de tais discursos. Penso que a própria concepção de leitura com a qual a Sala de Leitura opera é forjada ao longo da história, visto que tal concepção é vivida de forma inacabada, também provisória, que leva em consideração os movimentos externos e internos que influenciam diretamente seu trabalho.

Foi tentando acompanhar todo o movimento que os documentos, os discursos e a própria percepção de leitura desses espaços, que busquei tecer um olhar sobre as políticas que moldam as Salas de Leitura. Finalizo de forma provisória este trabalho com mais uma fala da coordenadora da Gerência de Mídia e Educação, fala esta que só me instiga a estudar e investigar mais esses espaços.

\begin{abstract}
"Desde quando muda uma gestão, de muito tempo 6 anos basicamente com diretrizes muito parecidas. Ainda que houvesse mudança, uma troca de gestão no meio do caminho. Era uma gestão de continuidade e foi eleito um sucessor indicado pela gestão da época. Então a equipe foi basicamente mantida, a diretriz, o trabaIho tinha a mesma direção. Mas quando você muda uma diretriz, acrescenta outros ingredientes, a rede tem um tempo para se acomodar, é um ano e meio de gestão. Então a gente está vivendo esse tempo, então as pessoas estão aplaudindo algumas coisas, estranhando outras, se adaptando a outras e isso faz parte do processo. E a sala de leitura nesse curto espaço de tempo já teve muita mudança".
\end{abstract}

\section{REFERÊNCIAS BIBLIOGRÁFICAS:}

AXER, Bonnie. Sala de Leitura: lugar de encontros ou desencontros? In: É preciso transver o mundo. $17^{\circ}$ COLE, 2009.

AXER, Bonnie. Juro que Vi: analisando a produção curricular através da mídia para crianças. In: Trajetórias e processos de ensinar e aprender: sujeitos, currículos e culturas, XIV ENDIPE, 2008.

AXER, Bonnie. \& VELLOSO Luciana. Discutindo Currículo e Cultura: A Série Juro Que Vi em Questão. In: Pedagogias sem fronteiras - $3^{\circ}$ Seminário Brasileiro de Estudos Culturais, 2008.

BALL. S. J. Diretrizes Políticas Globais e Relações Políticas Locais em Educação. 
Currículo sem fronteiras, v.1, n.2, p. 99-116, Jul/Dez 2001. Disponível em:

www.curriculosemfronteiras.org

BALL, Stephen; BOWE, Richard \& GOLD, Anne. Reforming Education \& Changing Schools: case studies in Policy Sociology. New York: Routledge, 1992.

BHABHA. H. (1998). O local da cultura. Belo Horizonte: Editora da UFMG.

CANCLINI, Nestor Garcia. Culturas Híbridas: estratégias para entrar e sair da modernidade. 4. ed. São Paulo: EDUSP, 2006.

LACLAU, Ernesto. La razón populista. Buenos Aires: Fondo de Cultura Económica de Argentina, 2005.

LACLAU, E. (1998). Desconstrucción, pragmatismo, hegemonía. In: C. Mouffe (org.). Desconstrucción y pragmatismo. Buenos Aires: Paidós.

LACLAU, E. \& MOUFFE, C. Hegemonia y estratégia socialista. Buenos Aires: Fondo de cultura econômica, 2004.

LOPES, Alice Casimiro. Política de currícuIo: recontextualização e hibridismo. In: Currículo sem Fronteiras, jul.-dez. 2005, v.5, n. 2, pp.50-64 (disponível em http://www.curriculosemfornteiras.org/artig os.htm).

. Cultura e diferenças nas políticas de currículo: a discussão sobre hegemonia. In: Trajetórias e processos de ensinar e aprender: sujeitos, currículos e culturas, XIV ENDIPE, 2008.

Currículo, Política, Cultura. In:

Convergências e tensões no campo da formação e do trabalho docente: currículo, XV ENDIPE, 2010.

MAINARDES, Jefferson. Abordagem do ciclo de políticas: uma contribuição para a análise de políticas educacionais. Revista Educação e Sociedade, Campinas, vol. 27, n.94, p. 47-69, Jan/Abr, 2006.

Por uma política da diferença: 0 que está em pauta em nossas políticas educacionais? Cadernos de Pesquisa, 36, 327 - 356. 2006.

Currículo: política, cultura e poder. Currículo sem Fronteiras, v.6, n.2, pp.98-113, Jul/Dez 2006.

Currículo e Diferença. In: Convergências e tensões no campo da formação e do trabalho docente: currículo, XV ENDIPE, 2010. (mimeo).

RIO DE JANEIRO. Secretaria Municipal de Educação. Núcleo Curricular Básico Multieducação. Rio de Janeiro, 1996.

Secretaria Municipal de Educação.

Multieducação temas em debate: Sala de Leitura. Rio de Janeiro, 2007.

ro, $11 / 01 / 96$.

Resolução SME no 1072. Rio de Janeiro, 31/03/2010. 